\title{
Atopic disease in the Hong Kong Chinese
}

\author{
Y. M. FUNG \\ M.B. B.Ch.
}

J. RHODES
M.D. F.R.C.P.

\author{
J. F. MAYBERRY \\ M.D. M.R.C.P.
}

R. G. NEWCOMBE

Ph.D. F.S.S.

\section{Department of Gastroenterology, University Hospital of Wales, Heath Park, Cardiff}

\section{Summary}

One hundred and sixty Chinese men and 96 women resident in Hong Kong completed a questionnaire about atopic disease and their responses were compared with replies from 500 Britons. Asthma and hayfever were less common in the Chinese and this could not be attributed to medical awareness as the results were similar in Chinese surgical patients and Chinese medical students. The role of heredity and environment may be assessed by studying Chinese people who have moved to Britain.

\section{Introduction}

Chinese people who move to Britain often report an increase in the frequency with which they develop asthma and hayfever. In this study we have attempted to record the prevalence of atopic diseases in Chinese people resident in Hong Kong and compared them with a similar British group.

\section{Method}

Two hundred and fifty-six Hong Kong residents completed a questionnaire in Chinese about atopic disease. They were asked whether they had ever suffered from asthma, hayfever, allergic rhinitis or eczema. Asthma was defined as 'breathlessness and wheezing'; allergic rhinitis was likened to 'hayfever with features of recurrent sneezing and a watery nasal discharge' and eczema was described as 'patches of dry red, inflamed, itchy skin'. A family history of atopic illness amongst parents or siblings of the patients was also recorded. One hundred and twenty-eight of the Chinese interviewed were surgical patients at the United Christian Hospital, Kowloon; the other 128 were clinical medical students at the University of Hong Kong. Eighty-five of the surgical patients were born in mainland China, while the remainder of the subjects were born in Hong Kong. Two hundred and twenty-two of the Chinese subjects came from families in the province of Kwangtung (Fig. 1). Surgical patients and medical students, although not matched for age and sex, were compared using a $\chi^{2}$ test (with one degree of freedom) to assess the effect of medical education on the survey.

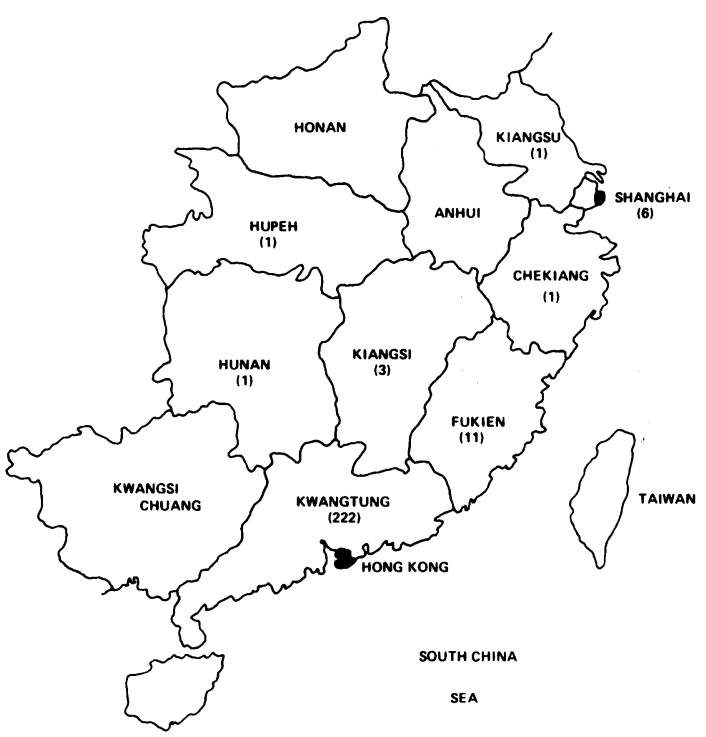

FIG. 1. Province of origin of Chinese subjects interviewed in the atopic survey. In 10 cases the province from which the subject's family originated was not known.

Five hundred British controls were chosen either from patients attending a fracture clinic at the Cardiff Royal Infirmary or their relatives. No Asian 
TABLE 1. Atopic disease in Hong Kong Chinese

\begin{tabular}{lccccccc}
\hline & \multicolumn{3}{c}{ Chinese } & & & \\
\cline { 2 - 5 } & $\begin{array}{c}\text { Medical students } \\
(\mathrm{n}=128)\end{array}$ & $\begin{array}{c}\text { Hospital patients } \\
(\mathrm{n}=128)\end{array}$ & $\begin{array}{c}\text { Total } \\
(\mathrm{n}=256)\end{array}$ & $\begin{array}{c}\text { British } \\
(\mathrm{n}=500)\end{array}$ & $\chi^{2}$ & $P$ value \\
\hline Asthma & 3 & 2 & 3 & 6 & 3.93 & $<0.05$ \\
Hayfever & 2 & 2 & 2 & 9 & 11.99 & $<0.001$ \\
Rhinitis & 22 & 15 & 18 & 11 & 6.78 & $<0.01$ \\
Eczema & 27 & 32 & 30 & 7 & 64.41 & $<0.001$ \\
Family history of atopy & 45 & 18 & 31 & 14 & 30.60 & $<0.001$ \\
\hline
\end{tabular}

Prevalence expressed as a percentage of atopic disease in 256 Chinese resident in Hong Kong compared with 500 Britons resident in Wales. The frequency was established by questionnaire. $\chi^{2}$ analysis was performed before transformation to percentages.

families were included. They completed a similar questionnaire in English, using the same definitions of atopic disease. Results were also compared using the $\chi^{2}$ test.

\section{Results}

Although the Chinese and British groups were not specifically matched for age and sex they were similar. There were 160 Chinese males with an average age of 45 years (range 8-79) compared with 300 British males of average age 40 years (range 15-75). The 96 Chinese women of mean age 33 years (range 16-86) were comparable to the 200 British women of mean age 35 years (range 12-75).

The prevalence of asthma, hayfever, allergic rhinitis and eczema differed significantly between the Chinese and British groups. Asthma and hayfever were both significantly less common in the Chinese population, whereas allergic rhinitis and eczema appeared to be more common than in the British group (Table 1).

The Chinese group consisted of surgical patients and medical students. Asthma, hayfever, allergic rhinitis and eczema appeared with similar frequency in the two groups. However, a family history of atopy was reported more often by the medical students than by the surgical patients. This difference was highly significant $\left(X^{2}=19.8 ; P<0.001\right)$. It is likely that the apparently high frequency of atopic family history in the Chinese medical student group accounts for the difference between the British and Chinese populations studied; the incidence in the Chinese patients (18\%) was not significantly different from that in the British sample (14\%).

\section{Discussion}

Asthma and hayfever appear to occur less frequently and eczema appears more frequently in Hong Kong Chinese than in Europeans. These findings are limited by cultural differences between British and Chinese populations. Traditional Chinese definitions of asthma and eczema are different from Western ones; but medical students receiving a Western education in Hong Kong reported a similar prevalence to that of Chinese surgical patients. It appears likely that asthma is less common in Chinese people resident in Hong Kong, whereas eczema seems to occur more frequently, but as eczema may be confused with other rashes, the significance of this latter observation is uncertain.

The use of a questionnaire to assess the prevalence of any disease in a community must be limited by interpretation of the diseases described. Although definitions were provided for most of the atopic diseases reviewed, confusion may have occurred between such entities as hayfever and allergic rhinitis. In any international comparison of diseases where uncertainty exists between recognized centres as in the definition of asthma, differences in prevalence must be interpreted with caution. Apparent differences in atopy could also well reflect differences in environmental allergenicity.

There are few studies of atopic disease in Chinese populations and these are limited by cultural differences in the definitions of these conditions. Asthma has been subdivided into four types-cold, feverish, mucus and deficiency asthma (A Barefoot Doctor's Manual, 1977). Of these, mucus asthma is clinically similar to the asthma definition used in our questionnaire. Liu et al. (1972) measured the period prevalence of asthma in the rural area of Shulin Tseng, Taipei, where they identified 318 cases during a 2year period. They were unable to confirm clearly the old Chinese belief that asthma often has a dietary cause, although from our study Chinese would appear to be less at risk of developing this condition. Hill (1968) reviewed 700 cases of atopic dermatitis from Hong Kong and noted that $18 \%$ of cases had a first degree relative with asthma or eczema, a surprisingly low figure as $18 \%$ of our generally nonatopic Chinese surgical patients had an affected 
relative and $45 \%$ of the healthy medical students claimed to have such a relative.

The role of heredity or environment in the development of asthma in the Chinese may be elucidated by further studies of Hong Kong Chinese who have emigrated to Britain in search of work or education.

\section{References}

A Barefoot Doctor's Manual (1977) Running Press, Philadelphia. LiU, H.M., Ko, R.T., LiN, T.M. \& CHEN, K.P. (1972) A retrospective study on bronchial asthma in Shulin township, Taipei county, Taiwan. Journal of the Formosan Medical Association, 71, 47.

HILL, B.H.R. (1968) The incidence of atopic eczema in Hong Kong. Journal of Asthma Research, 5, 199. 